\title{
Erratum to: Removing contaminants from transferred CVD graphene
}

Xiaojian Yang and Mingdi Yan $(\bowtie)$

Department of Chemistry, University of Massachusetts Lowell, Lowell, MA 01854, USA

(c) Tsinghua University Press and Springer-Verlag GmbH Germany, part of Springer Nature 2020

\section{Erratum to}

Nano Research 2020, 13(3): 599-610

https://doi.org/10.1007/s12274-020-2671-6

The NSF number in Acknowledgements in page 607 was unfortunately wrong,

\section{instead of}

The authors are grateful for the financial support from the National Science Foundation (No. CHE-1112436).

\section{It should read}

The authors are grateful for the financial support from the National Science Foundation (No. CHE-1808671).

The online version of the original article can be found at https://doi.org/10.1007/s12274-020-2671-6 